\title{
Comunicación entre menores y marcas en las redes sociales
}

\author{
Estrella MARTíNEZ RODRIGO \\ Universidad de Granada \\ emrodrigo@ugr.es \\ Lourdes SÁNCHEZ MARTíN \\ Universidad de Granada \\ lousanm@correo.ugr.es
}

Recibido: $14 / 07 / 2012$

Aceptado: 23/10/2012

\begin{abstract}
Resumen
Las redes sociales han permitido instaurar una relación fluida y estrecha entre anunciantes y usuarios. En estas plataformas, los consumidores pueden declararse seguidores de las marcas e interactuar con ellas; los anunciantes aprovechan la proactividad de los usuarios y aumentan así el número de impactos publicitarios. La marca Coca-Cola es uno de estos anunciantes que se han sabido instalar en las comunidades virtuales, específicamente en la red social Tuenti. Aunando al mayor número de seguidores, Coca-Cola se dirige a los adolescentes españoles. A lo largo de este estudio se analiza la relación entre la marca y los menores a través de la comunicación one to one, sus características propias, las diferencias participativas entre géneros y su posible contribución a la formación de un consumidor adolescente postcrisis.
\end{abstract}

Palabras clave: Coca-Cola, redes sociales, publicidad interactiva, adolescentes, prosumidor

\section{Communication between minors and brands on social networks}

\begin{abstract}
Social networks have allowed to establish a smooth, narrow between advertisers and users. On these platforms, consumers can declare followers and interact with brands, advertisers leverage the proactivity of users and thus increase the number of advertising impacts. Coca-Cola is one of the advertisers that have been known to establish in virtual communities, specifically the social network Tuenti. Combining the largest number of followers, Coca-Cola has a particularity: its communication is aimed at teenagers. Throughout this study we analyzed the relationship between the brand and the children through one to one communication, the characteristics of these messages, participatory gender differences and their possible contribution to the formation of a post-crisis consumer teenager.
\end{abstract}

Keywords: Coke, social networks, advertising, interaction, adolescents, prosumer

\section{Referencia normalizada}

MARTÍNEZ RODRIGO, Estrella y SÁNCHEZ MARTÍN, Lourdes (2012): “Comunicación entre menores y marcas en las redes sociales". Estudios sobre el mensaje periodístico. Vol. 18, núm. especial noviembre, págs.: 589-598. Madrid, Servicio de Publicaciones de la Universidad Complutense.

Sumario: 1. Introducción. 2. Objetivos y metodología. 3. La comunicación entre Coca-Cola y adolescentes en Tuenti; 3.1. Temáticas de Coca-Cola; 3.2. La interacción de los adolescentes con la marca; 3.3. El consumidor adolescente post-crisis. 4. Conclusiones. 5. Referencias bibliográficas.

\section{Introducción}

Las redes sociales son las plataformas más recientes y que han alcanzado una mayor popularidad en Internet. Con el objetivo de mantener un contacto inmediato y gratuito entre familiares y amigos mediante la creación de perfiles personales, estas plataformas han posibilitado una comunicación fluida, bidireccional y participativa (Calvo et al, 
2009: 82) entre usuarios. Dadas sus particularidades, los anunciantes se han insertado en estas redes, al considerar que pueden contribuir a la consecución de sus objetivos. Entre sus múltiples ventajas se encuentran una gran difusión a bajo coste y la posibilidad de que los consumidores expresen su opinión acerca de un producto.

Sin embargo, por el momento no se ha profundizado lo suficiente en la relación y comunicación real que se establece entre marcas y usuarios, especialmente, en aquellas redes sociales con un target mayoritariamente adolescente, que puede encontrarse desprovisto de la capacidad crítica suficiente para enfrentarse a los contenidos publicitarios. Los adolescentes desempeñan en estas plataformas el rol de receptores y, al mismo tiempo, asumen el de emisores. Nos parece por ello necesario centrarnos en la actividad real que surge en estas plataformas -con la pretensión de ir más allá de las meras afirmaciones que proclaman las ventajas que ofrecen dichas comunidades- $y$ analizar cómo los menores se desenvuelven en estos entornos.

Los menores españoles se agrupan sobre todo en Tuenti; surgida en 2006, es la única que permite el registro a partir de los catorce años, y en la actualidad cuenta con 13 millones de usuarios. En mayo de 2010 admite por primera vez el lanzamiento de páginas, además de los perfiles personales, permitiendo la entrada a marcas en la comunidad virtual, e iniciándose así la posibilidad de interactuar con los consumidores. Como señala Aced (2010: 25), los perfiles de marca se inician como: "una nueva funcionalidad que permite a sus miembros agruparse e interactuar en torno a un tema común. Por ejemplo, se puede crear una página de seguidores de un club de fútbol o de un grupo musical, una página donde compartir aficiones [...] Además, se crean también las páginas oficiales, con las que Tuenti abre las puertas a empresas y marcas, que de esta forma pueden tener un lugar donde interactuar con sus seguidores $\sin$ incumplir las normas de la plataforma".

Coca-Cola crea su página en Tuenti en el mismo mes de mayo de 2010, congregando rápidamente a un gran número de seguidores, que han aumentado en más de cien mil en tan solo un año, aproximándose a los cuatrocientos mil en agosto de este año. Recurre a diferentes formatos y soportes, que establecen dos tipos de comunicación:

- Comunicación interna: aquella que se da en su propio perfil o página de marca dentro de la red social, donde se congregan voluntaria y activamente todos sus seguidores, y en donde el anunciante tiene un control total de los contenidos publicados.

- Comunicación externa: aquella que está presente en la red social Tuenti, pero fuera de los límites propios de la página de marca de Coca-Cola. Esta publicidad puede ser visualizada por cualquier usuario de la red social, independientemente de que sea seguidor o no de la marca, y su objetivo es remitir a los usuarios al propio perfil para obtener así un mayor número de seguidores activos.

En la página de Coca-Cola en Tuenti podemos encontrar diferentes formatos y soportes destinados al público adolescente:

- Galería de imágenes: en un apartado propio la marca recoge las imágenes que ha publicado. En su mayoría, está constituida por carteles publicitarios, que destacan por su colorido y atractivo para el público adolescente. Las imágenes no 
se limitan al producto estrella de la marca, sino que también a diferentes productos comercializados por The Coca-Cola Company.

- Galería de vídeos: recoge todo el material audiovisual publicado por la marca en Tuenti, que son spots aparecidos con anterioridad en televisión, y dirigidos en su totalidad al target del que nos ocupamos. Al igual que las imágenes, se encuentran vídeos de Coca-Cola y también de otras marcas de la compañía como Fanta o Aquarius.

- Advergame: juego que gira en torno a la marca; capta la atención de los adolescentes y aumenta el número de seguidores de Coca-Cola. Se puede jugar tanto fuera como dentro de su página.

- Entertainment: se trata de contenidos de particular interés para los adolescentes, que remiten a través de enlaces, a contenidos externos a Tuenti ubicados en la página web oficial de Coca-Cola.

- Comunicación directa: se compone de mensajes escritos por Coca-Cola y respondidos por los interlocutores, que se publican en el tablón de la marca; aparecen los emitidos. Para su visualización es necesario declararse seguidor con antelación.

Este estudio se centra en el análisis de la comunicación directa entre la marca CocaCola en la red social Tuenti y los adolescentes. El formato nos resulta particularmente interesante, ya que la presencia de la marca en la red social es construida no solo por la marca, sino también por los menores.

\section{Objetivos y metodología}

Este trabajo presenta los resultados obtenidos de un estudio empírico y observacional con objeto de examinar la influencia que los perfiles publicitarios en las redes sociales ejercen sobre los adolescentes. Se analizan diferentes variables que denotan una clara influencia en la participación y relación que establecen ambos agentes.

Los objetivos de la investigación son, por tanto:

- Examinar aquellos elementos característicos de estos perfiles publicitarios y, en particular, conocer cómo Coca-Cola construye su perfil en la red social Tuenti y se dirige a los menores a través de los mensajes escritos.

- Comprender cómo la marca capta y mantiene la atención consiguiendo mantener una afiliación voluntaria por parte de los adolescentes a lo largo del tiempo.

- Discernir aquellos elementos que potencian la interacción de los usuarios con la marca.

El análisis se extiende desde el 9 de mayo al 9 junio de 2011, coincidiendo con la celebración del 125 aniversario de la marca. El universo se compone de todas las entradas emitidas por Coca-Cola y las respectivas contestaciones de los adolescentes. La muestra esta constituida por 27 entradas y 151 contestaciones de los menores, en donde se han analizado los siguientes aspectos:

- Las diversas temáticas utilizadas por la marca: de ahora en adelante se denominarán entradas con el fin de diferenciarlas de aquellos comentarios que la propia marca realiza dentro de una conversación ya iniciada, en donde los mensajes escritos se equiparan con los de los adolescentes. 
- La entonación de los mensajes de la marca mediante el uso de interrogaciones y exclamaciones, y su influencia en la participación de los adolescentes.

- Las diferencias o semejanzas entre las participaciones e interacciones masculinas y femeninas.

- El carácter positivo o negativo de los comentarios de los adolescentes, con el objetivo de conocer si estas páginas contribuyen o no al ejercicio de su capacidad crítica.

- La contribución de estos perfiles publicitarios a la generación de un prosumidor responsable.

\section{La comunicación entre Coca-Cola y adolescentes en Tuenti \\ 3.1. Temáticas de Coca-Cola}

Coca-Cola inicia un total de 27 conversaciones que se engloban dentro de 7 temáticas diferentes que en ocasiones se entremezclan, en torno a las cuales gira la comunicación:

- Cine: suelen difundir películas de interés adolescente. Normalmente, esta categoría se combina con la de obsequios, ofreciendo entradas.

- Deportes: se centra en la difusión de acontecimientos deportivos en donde la marca interviene como patrocinador u organizador. Por ejemplo: la Copa CocaCola de fútbol.

- Música: mensajes centrados en la difusión de los jingles de sus spots e indirectamente de aquellos grupos de música que los interpretan, que suelen ser de interés propiamente adolescente.

- Conciencia social: mensajes que promueven acciones de Responsabilidad Social Corporativa llevadas a cabo por la marca, generalmente sobre medio ambiente.

- Otros productos: publicidad de otros productos de la marca (Fanta, Aquarius, etc.).

- Obsequios: para conseguirlos, los adolescentes deben participar activamente en la conversación, lo que se utiliza como un elemento motivador.

- Aniversario: entradas referentes a sus 125 años.

Estas categorías se centran principalmente en los intereses adolescentes. Así, la música desempeña en la adolescencia "un papel en la socialización, formación de la identidad y autonomía" (Muñoz Rodríguez et al, 2011: 81). Según este autor, uno de cada dos adolescentes escucha música todos los días entre una y tres horas (57\%). De hecho, Coca-Cola remite en sus entradas a grupos actuales, cuyo público se enmarca en esa edad. Por lo general, estos grupos han realizado o versionado los jingles más conocidos de la marca.

También el cine despierta el interés de los menores. De hecho, el último Estudio General de Medios (2012) señala que el cine tiene la penetración más alta entre este target, comprendido entre los 14 y 19 años.

Los deportes inauguran asimismo una temática de su interés, más aún cuando las entradas se centran en actividades deportivas patrocinadas por la marca y desarrolladas para ellos.

Otras categorías destacan, sin embargo, por su relación con el ámbito publicitario. Es el caso de la temática "obsequios", que agrupa aquellas entradas en las que la 
marca ofrece regalos y/o premios, y "otros productos", desmarcándose de su producto Coca-Cola y publicitando otras de sus marcas como Fanta. Lo mismo ocurre con la categoría "conciencia social", que está estrechamente relacionada con las actividades de Responsabilidad Social Empresarial.

Entre todas estas temáticas, existen diferencias significativas: las más utilizadas son "obsequios" (70\%) y "música" (62\%), seguidas de "otros productos" (26\%), como puede verse en el gráfico:

Gráfico 1: Temáticas: entradas de Coca-Cola en Tuenti. Fuente: elaboración propia

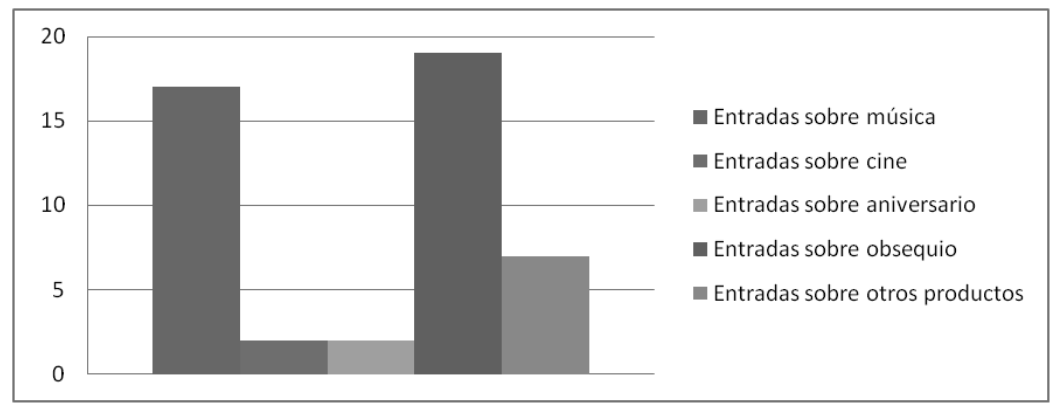

La mayor parte de las entradas recurren, por lo general, a una mezcla entre categorías, en donde predomina "obsequio-música" y que se traduce, sobre todo, en el regalo de entradas para conciertos. Son las temáticas más utilizadas para captar la atención de los adolescentes, dado el interés que despierta la música en estas edades y por la acción persuasiva que establece lo gratuito.

A continuación se analiza la interacción de los adolescentes y la influencia de estas temáticas en su participación.

\subsection{La interacción de los adolescentes con la marca}

Las 27 conversaciones iniciadas por Coca-Cola generan un total de 151 contestaciones, lo que indica un aumento muy considerable de la interacción de los adolescentes con respecto a la comunicación iniciada por Coca-Cola. Como puede verse, la participación es muy activa por parte de los menores, aunque no todos lo hacen por igual.

Gráfico 2: Participación por géneros. Fuente: elaboración propia

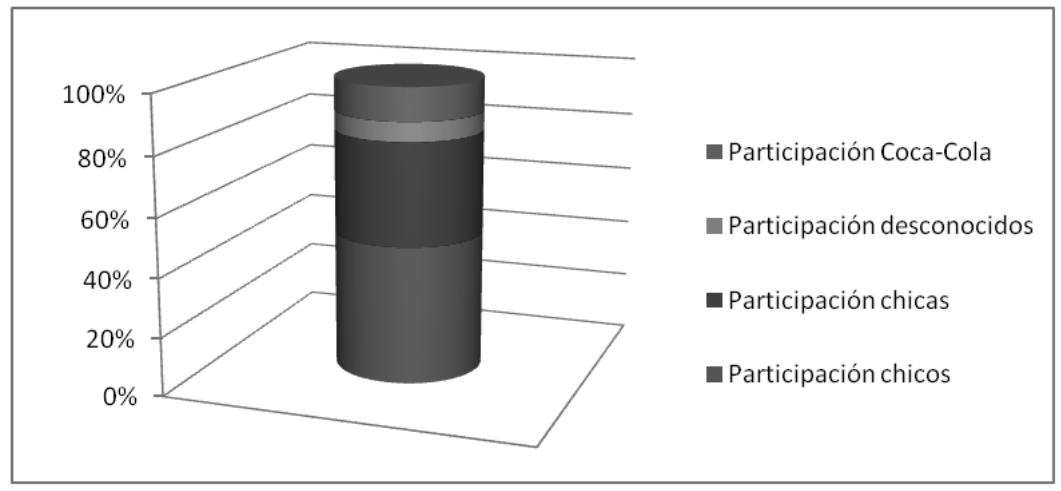


Los chicos adolescentes son, por lo general, más proclives a establecer una comunicación directa con Coca-Cola que las chicas: responden más rápida y activamente con independencia del tipo de entrada de la marca. No obstante, existen diferencias notables de participación entre géneros dependiendo de la temática de estas entradas.

A pesar de que, como hemos dicho, los varones son más proclives a interactuar con la marca, la categoría "música" atrae especialmente el interés femenino, duplicando las intervenciones con respecto a los chicos (Gráfico 3). En el resto de temáticas no existen diferencias significativas entre géneros. Por ello, podemos señalar que, mientras que los chicos interactúan sistemáticamente con independencia de la temática, las chicas solo lo hacen si el tema es realmente de su interés.

Gráfico 3: Participación por géneros en temática música. Fuente: elaboración propia

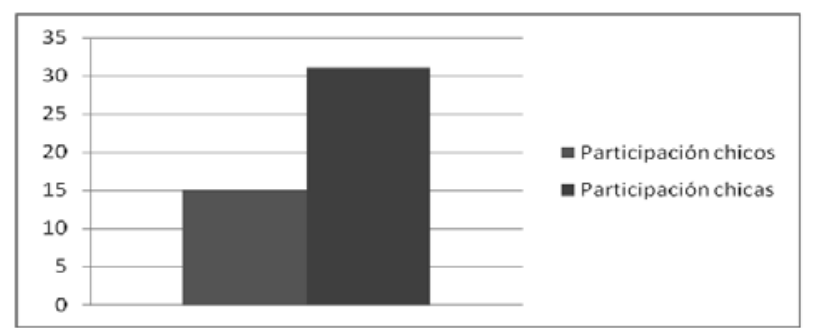

Otro aspecto que parece influir significativamente en la interacción y participación de los adolescentes es la entonación comunicativa de los mensajes de Coca-Cola. Así, en gran parte de sus entradas (84.1\%), se utilizan exclamaciones con el objetivo de reafirmar e interpelar a los adolescentes, y en un $27 \%$, recurre a las interrogaciones para formular preguntas directas incentivando su participación. Es interesante destacar que tanto exclamaciones como interrogaciones ejercen además un control sobre la conversación, pretendiendo limitar las respuestas a lo formulado en las entradas, sin que apenas se pueda actuar en contra de los intereses de la propia de la marca. Se ejerce así un control casi imperceptible sobre la comunicación con el objetivo de dirigir la conversación.

Gráfico 4: Influencia del uso de exclamaciones en la interacción. Fuente: elaboración propia

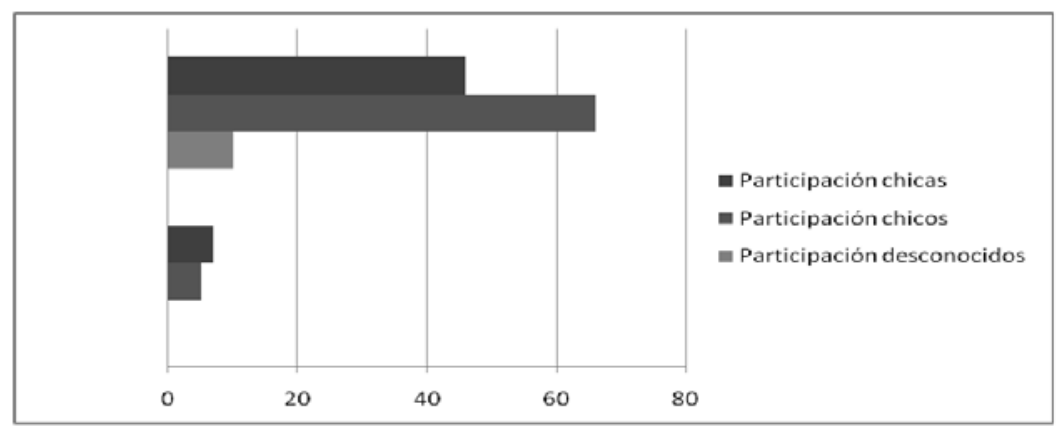

El uso de exclamaciones incentiva claramente la participación en la red social. Las entradas que las utilizan obtienen una participación muy alta: hasta un $92.9 \%$ en el caso de los chicos, y un $86.7 \%$ en el caso de las chicas, a diferencia de las que no las 
utilizan, en donde la participación de los usuarios es mínima, sin llegar en ningún caso al $10 \%$.

Las expresiones exclamativas por parte de Coca-Cola ascienden a un total de $81.4 \%$. Son utilizadas para enfatizar el mensaje, centrándose en aquellas palabras más

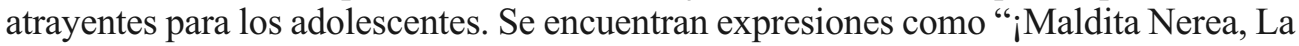
Musicalité, Pol 3.14 y muchos más en nuestro concierto por nuestros 125 años!", en donde se puede apreciar cómo estos signos resaltan aquellos términos que ya interesan a los menores. De este modo, la marca se muestra también involucrada con el grupo, expresando los mismos gustos que los de sus seguidores. Como señala García García et al (2010: 146), "los mensajes de Coca-Cola, [...] ofrecían y ofrecen, una visión soñadora y edulcorada de la vida, reflejando las modas, los hábitos y las costumbres sociales de cada momento" a las que se adhiere, según hemos visto, como principal partidario.

La entonación interrogativa se utiliza en prácticamente la mitad de las entradas analizadas. Algunas de las preguntas que emite la marca son, por ejemplo: "¿Quieres ver a Dani Martin en concierto?” o “¿Quieres asistir al Evento Del Año?”. A través de estas cuestiones Coca-Cola interpela de un modo directo a sus seguidores. Utiliza preguntas retóricas que, en su gran mayoría, tan sólo se podrían contestar con un sí o un no. A través de este carácter, se recurre a suavizar la entonación imperativa y a propiciar las intervenciones de los menores.

Por otra parte, debemos mencionar una entrada particularmente interesante por el elevado número de contestaciones tanto masculinas como femeninas: corresponde a la categoría "aniversario". En ella, Coca-Cola recuerda el día en el que su producto

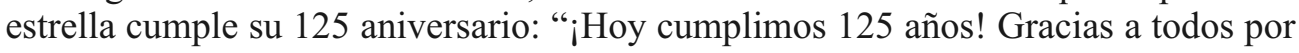
hacerlo posible :)". Los adolescentes responden a esta escueta entrada un total de 71 veces, abarcando así más del $45 \%$ de la participación total de los menores.

Estos datos nos muestran, a nivel cualitativo, cómo los menores se erigen como agentes publicitarios gratuitos de la marca, creando ellos mismos una imagen extremadamente positiva: felicitan y alaban, sin existir ni un solo comentario negativo. Por este motivo, debemos recordar el papel que ejercen los demás adolescentes y la presión del grupo sobre los individuos que lo conforman. Éstos acaban adoptando sus reglas y actitudes para sentirse aceptados e integrados (Berenguer, 2006).

Lo que resulta obvio es que las redes sociales han configurado una nueva relación entre las marcas y los consumidores (Martínez Rodrigo et al, 2012), permitiendo una comunicación directa, eficaz y una exposición consentida y continuada a los contenidos publicitarios. Por esta razón, debemos preguntarnos si la actividad que asumen los receptores, convirtiéndose también en emisores, potencia la capacidad crítica de los menores o si, por el contrario solo fomenta leales seguidores.

\subsection{El consumidor adolescente post-crisis}

El desarrollo de la Web 2.0 ha dado lugar a un término muy utilizado en los últimos años: consumidor post-crisis o prosumidor. Este concepto hace referencia al nuevo rol que asumen los consumidores, propiciado por el desarrollo de las tecnologías y promovido por distintos factores: la crisis económica, una mayor responsabilidad de la 
ciudadanía con respecto al consumo, etc. Simboliza "la transformación social hacia una cultura digital" (Biagini, 2008: 432). El prosumidor "ha pasado de estar aislado a estar conectado, de no estar informado a estarlo y de ser pasivo a ser activo" (Lenderman et al, 2008: 178). Actúa de un modo más comprometido con respecto al consumo. Al tener acceso a la información, tienen más criterio para la toma de decisiones (Lenderman, 2008). Se informa, compara, busca opiniones, valoración de otros, etc. $\mathrm{Y}$ teniendo en cuenta estos aspectos, ejerce o no el acto de consumo.

Las redes sociales, al ser unas plataformas particularmente comunicativas, se han creído propicias para la generación de este tipo de consumidor. Los usuarios de estas plataformas, a las que aplican regularmente parte de su tiempo, pueden interactuar con las marcas, con la competencia, con otros usuarios que ya han comprado un determinado producto, e informarse, valorando la necesidad de adquirirlo.

Sin embargo, las redes sociales y más concretamente los perfiles o páginas de marca, no parecen contribuir a la generación de una conciencia crítica entre los adolescentes, ya que en estos perfiles se reúnen, por lo general, los consumidores fieles de la marca, menos cuando se producen crisis de comunicación, en donde estos usuarios pueden convertirse rápidamente en detractores. De este modo, la mayor parte de las respuestas generadas por Coca-Cola en Tuenti son positivas con respecto a la marca y tan solo un comentario ha sido negativo en la muestra analizada.

Gráfico 5: Comentarios positivos, negativos y neutros. Fuente: elaboración propia

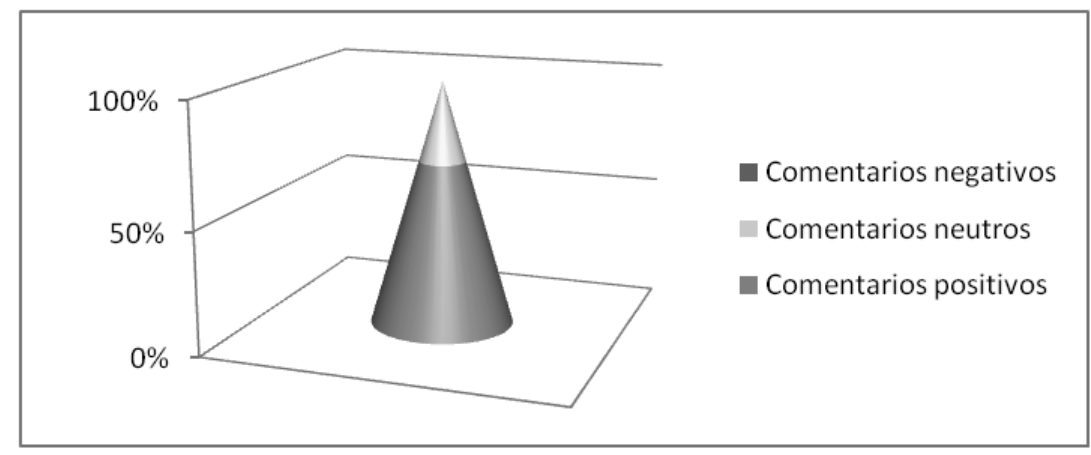

Por ello, el perfil de Coca-Cola en Tuenti parece más bien haber conseguido contribuir eficazmente a la generación de un pensamiento positivo y único con respecto al producto, frente a la disminución de una capacidad crítica por parte de los adolescentes. Los perfiles de marca les impiden conocer las características propias de los productos de la competencia, generando una concepción social positiva y una fidelización hacía el producto, dada la regularidad a la que los adolescentes son sometidos a impactos publicitarios. Coca-Cola destaca por la intensidad de sus impactos que ascienden hasta una media de dos entradas diarias.

Sin embargo, en caso de que se produjese una crisis de comunicación, estos adolescentes podrían convertirse rápidamente en detractores. Coca-Cola intenta prevenir tal crisis reforzando su imagen positiva mediante los comentarios de los propios menores a través de diferentes estrategias comunicativas en su perfil y. Así, elimina rápi- 
damente algunos de los comentarios negativos de los adolescentes, hecho que despierta las quejas de solo unos pocos adolescentes que acusan a la marca de ejercer la censura.

Como ya adelantábamos, la influencia que ejerce el grupo sobre los adolescentes es notable. Aunque formalmente cualquier individuo podría escribir críticas con respecto al producto, es comprensible que se vea frenado por la presión que ejerce el grupo y su interés en ser reconocido dentro de él. Además, esta comunicación se realiza en un determinado entorno social, aumentando así la influencia del grupo -todos se declaran fieles seguidores de la marca- sobre los individuos.

Por otra parte, no debemos olvidar que la única interacción que pueden realizar los adolescentes se sitúa dentro de las conversaciones ya iniciadas por Coca-Cola, sin la posibilidad de iniciar ellos cualquier otro tema, por lo que se ejerce una dirección sobre la comunicación con preguntas directas o indirectas que dificultan la reflexión crítica de los adolescentes sobre el producto y los contenidos.

Los menores se convierten dentro de estos perfiles en embajadores individuales de la marca, en pequeños agentes publicitarios que pueden influir a otros. El papel del prosumidor es en estos casos muy pobre, puesto que no existe argumentación posible por su parte, sino una persuasión continua y una exaltación de los gustos subjetivos de cada menor.

\section{Conclusiones}

Las redes sociales son las nuevas plataformas necesarias para la difusión de contenidos publicitarios. Cuando estas comunidades se caracterizan por configurarse como propiamente adolescentes logran una gran participación de los menores en las páginas de marca. La utilización de temáticas acordes con los intereses adolescentes es un gran aliciente que determina su actividad en estas plataformas. Coca-Cola ha sabido identificar claramente los asuntos de interés de los menores: obsequios, música, cine y deportes. Mientras que los chicos son más proclives a participar independientemente de la temática, las chicas muestran un interés más claro por cuestiones más específicas como la música.

Por otra parte, la entonación también es importante en la generación de respuestas: las entradas exclamativas son muy respondidas, frente al resto. Finalmente, debemos señalar que tanto por el rol que asume la marca en estas plataformas, como por sus estrategias comunicativas, los comentarios de los adolescentes son muy positivos, sin críticas patentes a lo largo de la muestra analizada. Por ello, podemos concluir que estos perfiles no contribuyen a la generación de consumidores críticos y responsables. Los menores, se exponen voluntariamente a los contenidos publicitarios convirtiéndose en nuevos agentes publicitarios gratuitos, que generan concepciones positivas en otros individuos, debido a la influencia que ejerce el grupo en estas edades.

\section{Referencias bibliográficas}

ACED, Cristina (2010): Redes sociales en una semana. Barcelona, Gestión 2000.

AIMC (2012): "Estudio General de Medios 2012 EGM". Abril de 2011 a marzo de 2012. En: http://www.aimc.es/spip.php?action=acceder_document\&arg=21 
$42 \& \mathrm{cle}=\mathrm{b} 22 \mathrm{e} 609 \mathrm{~d} 89429788961 \mathrm{ac} 85 \mathrm{cbf} 3892 \mathrm{c} 7 \mathrm{c} 0 \mathrm{c} 592 \mathrm{f} 8 \&$ file $\quad=$ pdf $\% 2$ Fresumegm112.pdf. [fecha de consulta: 21 de agosto de 2012]

BERENGER CONTRÍ, Gloria (2006): "Factores externos. Cultura, estratificación social, grupos de influencia y familia", en: MOLLÁ DESCALS, Alejandro et al.(Coord.): Comportamiento del consumidor. Barcelona, UOC, pp. 39-70.

BIAGINI, Hugo y ROIG, Arturo (2008): Diccionario del pensamiento alternativo. Argentina, Editorial Biblos.

CALVO MUÑOZ, Montse y ROJAS LLAMAS, Carolina (2009): Networking. Uso práctico de las redes sociales. Madrid, ESIC.

GARCÍA GARCÍA, Francisco, LLORENTE BARROSO, Carmen y GARCÍA GUARDIA, María Luisa (2010): "La construcción globalizada del logo-símbolo y la globalización de la marca a través del mismo". Historia y Comunicación Social, $\mathrm{n}^{\circ} 15, \mathrm{pp} .131-156$.

LENDERMAN, Max y SÁNCHEZ, Raúl (2008): Márketing experiencial. La revolución de las marcas. Madrid, ESIC.

MARTÍNEZ RODRIGO, Estrella; SÁNCHEZ MARTÍN, Lourdes (2012): "Publicidad en Internet: nuevas vinculaciones en las redes sociales". Vivat Academia. Revista de Comunicación Año XIV, pp. 469-480.

MUÑOZ RODRÍGUEZ, José Manuel (Ed.) OLMOS MIGUELÁÑEZ, Susana, HERNÁNDEZ MARTÍN, Azucena, CALVO ÁLVAREZ, Isabel y GONZÁLEZ RODERO, Luis (2011): Adolescencia y tiempo libre. Análisis y propuestas educativas en Salamanca. Salamanca, Ediciones Universidad de Salamanca.

\section{Dra. Estrella MARTíNEZ RODRIGO}

emrodrigo@ugr.es

Edif. Colegio Máximo. Campus de Cartuja s/n. 18017 Granada

Facultad de Comunicación y Documentación. Universidad de Granada.

Profesora de Comunicación audiovisual y Publicidad

\section{Lourdes SÁNCHEZ MARTÍN}

lousanm@correo.ugr.es

Edif. Colegio Máximo. Campus de Cartuja s/n. 18017 Granada

Facultad de Comunicación y Documentación. Universidad de Granada.

Investigadora de Comunicación Audiovisual y Publicidad 